\title{
Artificial Neural Network Approach to Predict the Abrasive Wear of AA2024-B ${ }_{4}$ C Composites
}

\author{
A. Canakci ${ }^{1, *}$, T. $\operatorname{Varol}^{1}$, S. Ozsahin ${ }^{2}$, S. Ozkaya ${ }^{1}$ \\ ${ }^{1}$ Department of Metallurgical and Materials Engineering, Engineering Faculty, Karadeniz Technical University, Turkey \\ ${ }^{2}$ Department of Industrial Engineering, Engineering Faculty, Karadeniz Technical University, Turkey
}

Copyright (C) 2014 Horizon Research Publishing All rights reserved.

\begin{abstract}
A neural network (ANN) model was developed to predict the abrasive wear behavior of AA2024 aluminum alloy matrix composites reinforced with $\mathrm{B}_{4} \mathrm{C}$ particles. $\mathrm{A} 12024-\mathrm{B}_{4} \mathrm{C}$ powder mixtures with various reinforcement volume fractions $(3-10 \%)$ and particle sizes $(29 \mu \mathrm{m}$ and 71 $\mu \mathrm{m})$ were prepared and $\mathrm{Al} 2024-\mathrm{B}_{4} \mathrm{C}$ composites were produced by stir-casting technique. The model was based on three layer neural network with feed forward back propagation learning algorithm. A sigmoid transfer function was developed and found to be suitable for analyzing the abrasive wear behavior of composites with the least error. The training data are collected by the experimental setup in the laboratory. The trained model was used to study the effect of ceramic particle size and volume fraction on the abrasive wear of $\mathrm{Al} 2024-\mathrm{B}_{4} \mathrm{C}$ composites. By comparing the predicted values with the experimental data, it was demonstrated that the well-trained feed forward back propagation ANN model is a powerful tool for prediction of abrasive wear behavior of $\mathrm{Al} 2024-\mathrm{B}_{4} \mathrm{C}$ composites.
\end{abstract}

Keywords A. Metal-matrix Composites, Wear, Computational Modelling, Casting

\section{Introduction}

Aluminum-matrix composites (AMCs) reinforced with particles and whiskers are widely used for high performance applications such as in automotive, military, aerospace and electricity industries because of their improved physical and mechanical properties [1]. Hard reinforcement phases are added to Al matrix in order to overcome the poor wear resistance and improve their high specific strength. Ceramic particle-reinforced aluminum matrix composites are being considered for higher mechanical and tribological properties over the conventional aluminum alloys, and therefore, these composites have gained extensive applications in automotive and aerospace industries [2].

Based on the previous studies $[3,4], \mathrm{B}_{4} \mathrm{C}$ reinforcement particles have been recently used as reinforcements for $\mathrm{Al}$ matrix composites where the wear performance is of high importance. While other studies also have investigated the addition of other reinforcing particles such as $\mathrm{TiB}_{2}, \mathrm{Al}_{2} \mathrm{O}_{3}$, $\mathrm{SiC}$, and $\mathrm{TiC}$ [5], using $\mathrm{B}_{4} \mathrm{C}$ offers the superior properties of this reinforcing phase among which high strength, low density, extremely high hardness, and good chemical stability are mentionable $[6,7]$. The ceramic particle-reinforced composites are being produced by different methods, such as stir casting [8], powder metallurgy [9]. Among these methods, stir casting is considered to be easily adaptable and economically viable due to its low processing cost and high production rate. An additional benefit of this process is the near-net shape formation of the composites [10].

Neural networks are useful tools for information processing and many other applications. Due to their unique features they can be used to solve complex problems that cannot be handled by analytical approaches, even problems whose underlining physical and mathematical models are not well-known. The use of an artificial neural network (ANN) is one of the most powerful modeling techniques, and in conjunction with a statistical approach, ANN is likely to be suitable for the prediction of the mechanical, tribological and the physical properties of MMCs [11-13]. Ozyurek et al. [11] studied that the wear properties of the $\mathrm{SiC}$ particle reinforced Al356 matrix composite materials both by experimental and Artificial Neural Network (ANN) model. They compared the experimental results and the ANNs predicted data and it was observed that $\mathrm{R}^{2}$ was 0.9855 . Rashed and Mahmoud [12] investigated that prediction of wear behavior of $\mathrm{Al} / \mathrm{SiCp}$ MMCs using neural networks. They reported that ANN is an effective tool in the prediction of the properties of MMCs, and quite useful instead of time-consuming experimental processes. Shabani and Ali Mazahery [13] studied that prediction of wear properties in A356 matrix composite reinforced with $\mathrm{B}_{4} \mathrm{C}$ particulates. According to their results, predictions of ANN are consistent with experimental measurements for A356 composite and considerable savings in terms of cost and time could be obtained by using neural network model. Recently, there has been increased interest in ANN modeling within different fields of materials science 
[14]. This is a promising field of research for predicting experimental trends and has become increasingly popular over the last few years because it can often solve problems much faster compared with other approaches with the additional ability to learn from a small set of experimental data [11].

The aim of the present work was to investigate the effect of $\mathrm{B}_{4} \mathrm{C}$ particles content, size and sliding time on the abrasive wear behavior of ceramic particle-reinforced composites with the use of artificial neural networks.

\section{Material and Methods}

The AA2024 alloy was supplied commercially with the chemical composition (in weight percent) of $4.850 \% \mathrm{Cu}$, $1.310 \% \mathrm{Mg}, 0.667 \% \mathrm{Mn}, 0.254 \% \mathrm{Fe}, 0.110 \% \mathrm{Si}, 0.079 \% \mathrm{Zn}$, $0.033 \% \mathrm{Cr}, 0.008 \% \mathrm{Ti}$ and balance Al. AA2024 alloy with a theoretical density of $2.78 \mathrm{~g} / \mathrm{cm}^{3}$ was used as the matrix material. The $\mathrm{B}_{4} \mathrm{C}$ particles with different average particle sizes of $71 \mu \mathrm{m}$ which varies between 53 and $90 \mu \mathrm{m}$ and 29 $\mu \mathrm{m}$ which varies between 16.5 and $49 \mu \mathrm{m}$ and a density of $2.51 \mathrm{~g} / \mathrm{cm}^{3}$ were used as the reinforcements. All samples used in this investigation were produced by stir-casting technique and named as shown in Table 1.

Table 1. Characteristics of the composite materials

\begin{tabular}{|ccc|}
\hline Name & Composition & $\begin{array}{c}\text { Average size of } \mathbf{B}_{4} \mathbf{C} \\
\text { particles }(\boldsymbol{\mu m})\end{array}$ \\
\hline 2024 & Al2024 & 71 \\
\hline $2024-\mathrm{K}_{3}$ & Al2024-3 vol.\% & 71 \\
\hline $2024-\mathrm{K}_{5}$ & Al2024-5 vol.\% & 71 \\
\hline $2024-\mathrm{K}_{7}$ & Al2024-7 vol.\% & 71 \\
\hline $2024-\mathrm{K}_{10}$ & Al2024-10 vol.\% & 71 \\
\hline $2024-\dot{\mathrm{I}}_{3}$ & Al2024-3 vol.\% & 29 \\
\hline $2024-\dot{I}_{5}$ & Al2024-5 vol.\% & 29 \\
\hline $2024-\dot{\mathrm{I}}_{7}$ & Al2024-7 vol.\% & 29 \\
\hline $2024-\dot{I}_{10}$ & Al2024-10 vol.\% & 29 \\
\hline
\end{tabular}

The experimental density of the composite samples was measured using Archimede's method. The theoretical density was calculated using the mixture rule according to the volume fraction of the $\mathrm{B}_{4} \mathrm{C}$ particles. The porosities of the composites were then evaluated based on the difference between the theoretical and the observed density of each sample. The hardness of the samples was measured using Brinell hardness method under a load of $125 \mathrm{~kg}$ for a dwell time of $20 \mathrm{~s}$. The microstructure of the produced ingots was examined using a SEM in order to determine the distribution of the $\mathrm{B}_{4} \mathrm{C}$ particles in the matrix and presence of porosity. For this purpose, the samples were sectioned first and then prepared by the standard metallographic technique.

The three-body wear tests were performed using a blockon- disc type test rig (Plint \& Partners Wear Tester) at ambient temperature in the laboratory conditions. Wear tests were carried out under a normal load of $92 \mathrm{~N}$ and with total sliding time of 2,080 $\mathrm{s}$. The samples were tested in five steps: $200,670,1,140,1,610$ and 2,080 s. The wear resistance was measured by weight loss technique using a balance with an accuracy of $\pm 0.01 \mathrm{mg}$. For this measurement, the tested samples were first cleaned in an ultrasonic bath with acetone and then dried below $100^{\circ} \mathrm{C}$. The weight loss values were then converted into volume loss values using the density of the samples. For each test condition, at least three tests were performed and the average of them was given. The tests were conducted at a sliding speed of $0.314 \mathrm{~ms}^{-1}$.

After wear tests, the specific wear rates were calculated using the Eq. 1 [15]:

$$
\mathrm{W}=\Delta \mathrm{m} /(\delta . F n . v . t)=\mathrm{V} /(\text { Fn.v.t })
$$

Where $\mathrm{W}$ is the specific wear rate, $\Delta \mathrm{m}$ is the mass loss, $\delta$ is the density, $\mathrm{V}$ is the volume loss, Fn is the normal load, $\mathrm{v}$ is the sliding velocity and $t$ is the sliding time. The roughness of the composite surfaces was evaluated by surface roughness measurements using a stylus-type instrument. Before the wear tests, each sample surface was ground with a 800 -grade abrasive paper for being comparison of surface roughness of each sample.

\subsection{Artificial Neural Network (ANN) Model}

The first step is training the network and the second step is testing the network using the experimental datas. In this step, training data must be separate from the test data. In the training step, constant input parameters are entered in order to have appropriate output data by using weight values. The weight values gain meaning after the training step. These weight values are the random values before the network is taught. When the training comes to sufficient level it stops and test data is calculated with ANN by using weight values. The 'training data set' of input and output data are cycled 'through' the network until the errors in the network outputs are reduced to an acceptable level. Once the network is trained, it can be used to predict the outputs from a set of inputs that was not included in the training data set. Although ANNs are effective at interpolating within a data-base, they are unreliable at extrapolating beyond the range of the data-base [16]. The basic neural cell model is shown in Fig. 1. In the artificial neuron, the main components include: weights, addition function, activation function and outputs.

The neurons are arranged in three layers. First the input layer, where the input data set is provided; second the hidden layer(s), which is the brain of the system and finally the output layer, which dictates the outcome of the system. Each neuron transfers the data or signal to the next neuron, which is manipulated by the 'transfer function', 'weight' and 'bias' embedded in the neuron [17]. 


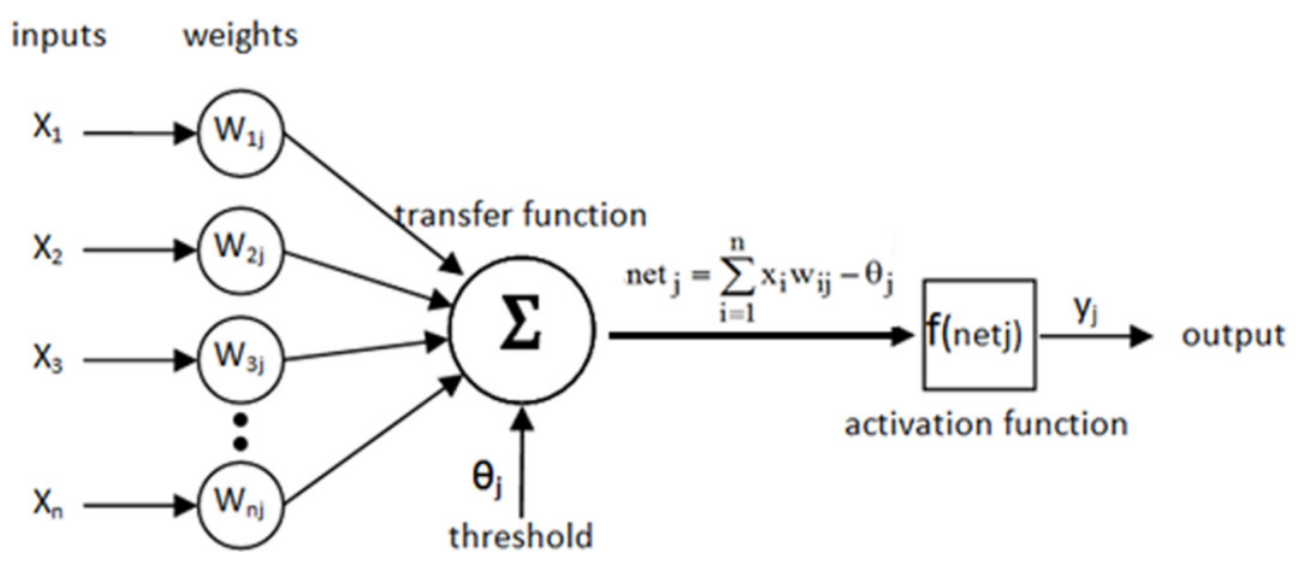

Figure 1. Artificial neural cell (artificial neuron).

Inputs $\left(\mathrm{x}_{\mathrm{i}}\right)$ are data, obtained from the external environment or the other artificial neurons. The quantities $\left(\mathrm{w}_{\mathrm{ij}}\right)$ demonstrate the effect of a data point arrives at an artificial neural cell. The addition function (threshold function, Eq.2) (net $_{\mathrm{j}}$ ) calculates the net input on a neural cell. The sigmoid function (Eq.3) is the most common activation function in the ANN because it combines nearly linear behavior, curvilinear behavior, and nearly constant behavior. All of these components depend on the value of the input [11]. In the cell model, a bias with +1 value may increase the net input or polarization threshold input $\left(\theta_{\mathrm{j}}\right)$ by a value of, -1 , thereby decreasing the net input according to:

$$
\text { net }_{j}=\sum_{\mathrm{i}=1}^{\mathrm{n}} \mathrm{x}_{\mathrm{i}} \mathrm{w}_{\mathrm{ij}}-\theta_{\mathrm{i}}
$$

where $x_{i}$ indicates the $i$. input, $w_{i j}$ is the connection weight from $\mathrm{j}$. element to $\mathrm{i}$. element, $\theta_{\mathrm{j}}$ is the polarization value (negative of the threshold value), and $n$ indicates the sent input signal of the artificial neuron number in the previous layer.

The artificial neuron output value, which depends on the selected activation function, employs a sigmoid function as the activation function [18] and is calculated using Eq. 3. The produced output is sent via network connections between different cells, as explained by:

$$
y_{j}=f\left(\text { net }_{j}\right)=\frac{1}{1+e^{- \text {net }_{j}}}
$$

When more than one parallel processing artificial neuron is necessary, a multi-layered network structure is used. Fig. 2 shows a typical ANN architecture which consist of three layers: one input layer, one hidden layer and an output neuron.

In the structure of a multi-layered ANN, there are mainly three layers which consist of an input layer with artificial neural cells that are connected to each other in different ways, an output layer and a hidden layer (intermediate layer). The input layer is the first layer and is responsible for receiving the in-coming data for the ANN and for delivering the data to intermediate layer. The hidden layer processes the information that comes from the input layer and sends it to the output layer. The neurons in the hidden layer do not have any connection to the external environment. The output layer processes the information coming from the intermediate layer and produces output data for the input layer of the network, which sends this to the outside world.

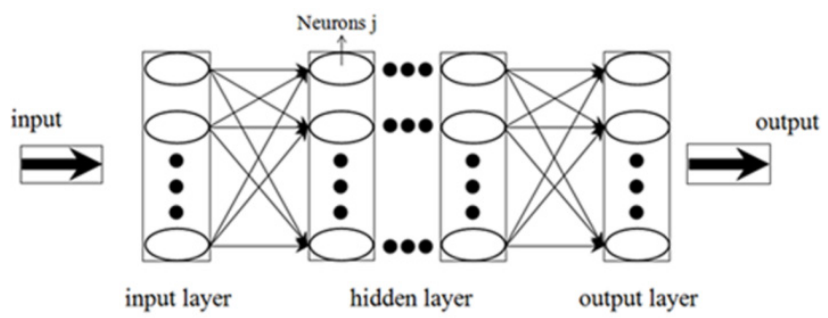

Figure 2. A typical multi-layered ANN architecture.

\subsection{Collecting the Experimental Data}

The training data were used in the forecast model, as shown in Table 2.

The root mean squared error (RMSE) and the mean absolute percentage error (MAPE) values are calculated from Eqs.4 and 5 [19]. Models that produce the best estimated values were selected as the forecasting models.

$$
\begin{gathered}
R M S E=\sqrt{\frac{1}{N} \sum_{i=1}^{N}\left(t_{i}-t d_{i}\right)^{2}} \\
\mathrm{MAPE}=\frac{1}{\mathrm{~N}}\left(\sum_{\mathrm{i}=1}^{\mathrm{N}}\left[\left|\frac{\mathrm{t}_{\mathrm{i}}-\mathrm{td}_{\mathrm{i}}}{\mathrm{t}_{\mathrm{i}}}\right|\right]\right) \times 100
\end{gathered}
$$

where $t_{i}$ is the real value, $\operatorname{td}_{i}$ is the model prediction value and $\mathrm{N}$ is the number of testing data.

Table 2 shows the actual values, degrees of deviation, percentage error rates, RMSE and MAPE calculated using the estimated models. 
Table 2. Experiment data and predicted output from the ANN network for training set

\begin{tabular}{|c|c|c|c|c|c|c|c|c|c|c|c|c|}
\hline \multirow{2}{*}{ Sample ID } & \multirow{2}{*}{$\begin{array}{l}\text { Particle } \\
\text { size }\end{array}$} & \multirow{2}{*}{$\begin{array}{c}\text { Sliding } \\
\text { time }\end{array}$} & \multirow{2}{*}{$\begin{array}{l}\text { Volume } \\
\text { fraction }\end{array}$} & \multicolumn{3}{|c|}{ Volume loss } & \multicolumn{3}{|c|}{ Specific wear rate } & \multicolumn{3}{|c|}{ Surface roughness } \\
\hline & & & & Measured & Predicted & \% Error & Measured & Predicted & \% Error & Measured & Predicted & \% Error \\
\hline 1 & 71 & 200 & 0 & 1.349 & 1.501 & -11.28 & 0.233 & 0.232 & 0.36 & 4.699 & 4.672 & 0.58 \\
\hline 2 & 71 & 200 & 3 & 1.082 & 1.163 & -7.53 & 0.187 & 0.190 & -1.35 & 4.275 & 4.334 & -1.37 \\
\hline 4 & 71 & 200 & 7 & 0.904 & 0.894 & 1.16 & 0.156 & 0.159 & -1.63 & 3.742 & 3.765 & -0.62 \\
\hline 5 & 71 & 200 & 10 & 0.543 & 0.629 & -15.88 & 0.094 & 0.094 & -0.25 & 3.344 & 3.345 & -0.03 \\
\hline 6 & 71 & 670 & 0 & 3.417 & 3.517 & -2.92 & 0.177 & 0.179 & -1.00 & 5.992 & 6.082 & -1.51 \\
\hline 8 & 71 & 670 & 5 & 2.438 & 2.506 & -2.77 & 0.126 & 0.125 & 1.06 & 5.939 & 5.817 & 2.05 \\
\hline 9 & 71 & 670 & 7 & 2.170 & 2.218 & -2.22 & 0.112 & 0.110 & 1.89 & 3.795 & 3.788 & 0.18 \\
\hline 12 & 71 & 1140 & 3 & 4.600 & 4.513 & 1.90 & 0.140 & 0.135 & 3.61 & 5.363 & 5.351 & 0.22 \\
\hline 13 & 71 & 1140 & 5 & 4.063 & 3.986 & 1.90 & 0.123 & 0.117 & 5.17 & 5.952 & 6.039 & -1.47 \\
\hline 15 & 71 & 1140 & 10 & 1.901 & 1.742 & 8.38 & 0.058 & 0.055 & 4.77 & 5.393 & 5.382 & 0.21 \\
\hline 16 & 71 & 1610 & 0 & 6.924 & 6.749 & 2.53 & 0.149 & 0.150 & -0.79 & 6.299 & 6.246 & 0.83 \\
\hline 18 & 71 & 1610 & 5 & 5.146 & 5.152 & -0.12 & 0.111 & 0.114 & -2.47 & 5.960 & 5.908 & 0.87 \\
\hline 20 & 71 & 1610 & 10 & 2.263 & 2.242 & 0.94 & 0.047 & 0.051 & -8.31 & 5.651 & 5.666 & -0.26 \\
\hline 22 & 71 & 2080 & 3 & 7.305 & 7.392 & -1.19 & 0.122 & 0.126 & -3.59 & 5.618 & 5.604 & 0.24 \\
\hline 23 & 71 & 2080 & 5 & 6.501 & 6.577 & -1.17 & 0.108 & 0.111 & -2.48 & 5.517 & 5.571 & -0.97 \\
\hline 24 & 71 & 2080 & 7 & 5.877 & 5.841 & 0.62 & 0.098 & 0.099 & -0.61 & 4.202 & 4.202 & -0.01 \\
\hline 25 & 71 & 2080 & 10 & 2.806 & 2.908 & -3.63 & 0.047 & 0.046 & 2.90 & 5.051 & 5.047 & 0.08 \\
\hline 27 & 29 & 200 & 3 & 1.263 & 1.173 & 7.14 & 0.219 & 0.217 & 0.99 & 3.985 & 3.922 & 1.58 \\
\hline 28 & 29 & 200 & 5 & 1.083 & 0.988 & 8.77 & 0.188 & 0.190 & -1.05 & 3.929 & 3.987 & -1.49 \\
\hline 29 & 29 & 200 & 7 & 0.995 & 0.843 & 15.30 & 0.172 & 0.168 & 2.35 & 4.236 & 4.199 & 0.86 \\
\hline 31 & 29 & 670 & 0 & 3.417 & 3.312 & 3.07 & 0.177 & 0.174 & 1.51 & 5.992 & 5.910 & 1.38 \\
\hline 32 & 29 & 670 & 3 & 2.886 & 2.898 & -0.41 & 0.149 & 0.154 & -3.37 & 4.736 & 4.753 & -0.37 \\
\hline 34 & 29 & 670 & 7 & 2.170 & 2.137 & 1.53 & 0.112 & 0.114 & -2.13 & 5.395 & 5.540 & -2.69 \\
\hline 35 & 29 & 670 & 10 & 1.629 & 1.644 & -0.90 & 0.084 & 0.086 & -2.16 & 5.141 & 5.080 & 1.18 \\
\hline 36 & 29 & 1140 & 0 & 5.036 & 5.113 & -1.53 & 0.153 & 0.156 & -2.01 & 6.193 & 6.231 & -0.61 \\
\hline 38 & 29 & 1140 & 5 & 3.973 & 4.006 & -0.82 & 0.121 & 0.119 & 1.88 & 4.958 & 4.960 & -0.03 \\
\hline 39 & 29 & 1140 & 7 & 3.436 & 3.570 & -3.89 & 0.104 & 0.105 & -1.37 & 5.934 & 5.843 & 1.53 \\
\hline 41 & 29 & 1610 & 0 & 6.924 & 6.790 & 1.94 & 0.149 & 0.141 & 5.39 & 6.299 & 6.277 & 0.35 \\
\hline 42 & 29 & 1610 & 3 & 5.682 & 5.973 & -5.11 & 0.122 & 0.127 & -4.02 & 5.312 & 5.340 & -0.52 \\
\hline 44 & 29 & 1610 & 7 & 4.702 & 4.748 & -0.97 & 0.101 & 0.103 & -1.82 & 5.758 & 5.764 & -0.11 \\
\hline 45 & 29 & 1610 & 10 & 3.983 & 3.956 & 0.67 & 0.086 & 0.085 & 1.04 & 4.960 & 5.006 & -0.92 \\
\hline 46 & 29 & 2080 & 0 & 8.004 & 8.012 & -0.10 & 0.133 & 0.134 & -0.70 & 6.699 & 6.733 & -0.50 \\
\hline 48 & 29 & 2080 & 5 & 6.872 & 6.724 & 2.15 & 0.114 & 0.109 & 4.29 & 5.154 & 5.124 & 0.58 \\
\hline \multirow[t]{3}{*}{50} & 29 & 2080 & 10 & 5.340 & 5.272 & 1.28 & 0.089 & 0.088 & 1.19 & 4.511 & 4.496 & 0.33 \\
\hline & \multicolumn{3}{|c|}{ MAPE } & \multicolumn{3}{|c|}{3.580} & \multicolumn{3}{|c|}{2.338} & \multicolumn{3}{|c|}{0.781} \\
\hline & \multicolumn{3}{|c|}{ RMSE } & \multicolumn{3}{|c|}{0.103} & \multicolumn{3}{|c|}{0.003} & \multicolumn{3}{|c|}{0.054} \\
\hline
\end{tabular}

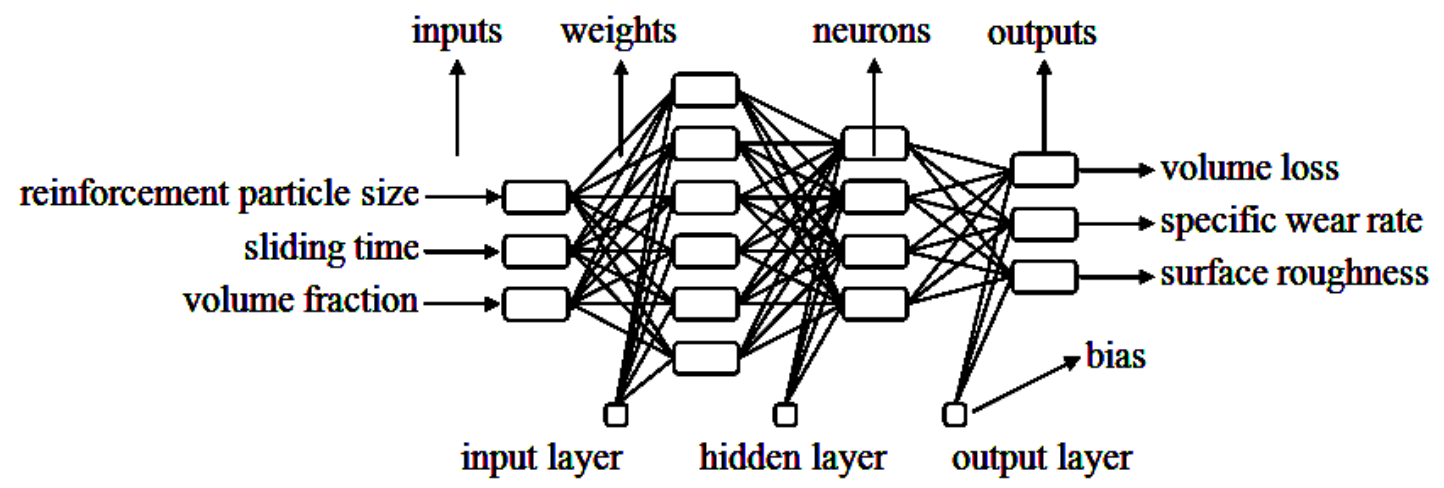

Figure 3. ANN architecture selected as prediction model for the volume loss, specific wear rate and surface roughness. 


\subsection{Neural Network Architecture}

Figure 3 shows the ANN models containing one input layer, two hidden layers and one output layer.

The minimum error was obtained at 6 nodes at the first hidden layer and 4 nodes at the second hidden layer for the prediction model of the wear properties. The selected ANN model represents the prediction model that produced the closest values to the measured values for the volume loss, specific wear rate and surface roughness. The reinforcement particle size, sliding time and volume fraction were used as the input variables, while the volume loss, specific wear rate and surface roughness were used as the output variables in the ANN models. The processing element numbers (neurons) of the hidden layers were 6 and 4 for the model in Fig. 3.

\subsection{Network Training and Testing}

To ensure an equal contribution of each parameter in the model, the training and test datasets were normalized $(-1,1$ range) due to the use of the hyperbolic tangent sigmoid function in the model and network, which allowed the data to be translated into the original value, with a reverse normalizing process for the interpretation of the results. The normalization (scaling) operations were carried out using Eq. 6:

$$
X_{\text {norm }}=2 \times \frac{X-X_{\text {min }}}{X_{\text {max }}-X_{\text {min }}}-1
$$

where $X_{\text {norm }}$ is the normalized value, $X$ is the true value of the variable, $X_{\min }$ is minimum value of the data set and $X_{\max }$ is the maximum value of the data set.

It was decided that the 0.001 targeted error values would be sufficient for the training of the artificial neural network. The number of epochs after which the training model was stopped is 541 .

\section{Results and Discussion}

\subsection{Abrasive Wear Behavior of Al2024-B $\mathrm{B}_{4} \mathrm{C}$ Composite}

The size of $\mathrm{B}_{4} \mathrm{C}$ particles were changed between 29 and 71 $\mu \mathrm{m}$, and the effect of $\mathrm{B}_{4} \mathrm{C}$ size on the volume loss was investigated and the results are depicted in Table 2 and 3. It can be seen from the Table that the volume loss increases with increasing sliding time, with decreasing particle content and with decreasing particle size of $\mathrm{B}_{4} \mathrm{C}$. The volume loss of the unreinforced alloy was found to be much higher than that of the composites. The volume loss of the composites reinforced with $71 \mu \mathrm{m} \mathrm{B}{ }_{4} C$ particles is lower than that of the composites reinforced with $29 \mu \mathrm{m} \mathrm{B} 4 \mathrm{C}$ particles. This can be attributed to the better protection to the matrix from large reinforcements against abrading particles [20]. The result indicates that the larger the reinforcement particle, the lower the volume loss for the composites reinforced with the same volume fraction of $\mathrm{B}_{4} \mathrm{C}$ particle [21]. The effect of $\mathrm{B}_{4} \mathrm{C}$ particle volume fraction on the volume losses of the composites was given in Table 2 and 3. The particle size of $\mathrm{B}_{4} \mathrm{C}$ reinforcement had a considerable effect on the abrasion wear resistance of the composites, which is increased with increasing particle size. Additionally, the volume loss of the composites reinforced with $71 \mu \mathrm{m} \mathrm{B}_{4} \mathrm{C}$ particles is lower than that of the composites reinforced with $29 \mu \mathrm{m} \mathrm{B} \mathrm{B}_{4} \mathrm{C}$ particles. In the case of $2024 \mathrm{Al}$ alloy, it is considered that $\mathrm{SiC}$ abrasives in the suspension mixture could penetrate easily into the soft 2024 Al matrix alloy during sliding, resulting in excessive material removal from the surface. In the composites, the hard reinforcing $\mathrm{B}_{4} \mathrm{C}$ particles resist the micro-cutting action of the abrasives effectively, resulting in low material removal from the surface [22].

The change of specific wear rate values with $\mathrm{B}_{4} \mathrm{C}$ particle content and particle size are given in Table 2 and 3. The composites with smaller $\mathrm{B}_{4} \mathrm{C}$ size exhibited the lower resistance for the same fraction of $\mathrm{B}_{4} \mathrm{C}$ with different sizes. For materials characterized by particles, dispersed in a soft matrix, a decrease in the particle mean free path by reducing the particle size results in an increase the hardness and a decrease in wear rate of composites [23, 24]. The higher wear rate for the composites with small particles sizes is attributed to the particle-matrix interfacial area. The interfacial area in case of a smaller particle size is relatively large, which increases the chance for the small $\mathrm{B}_{4} \mathrm{C}$ particles to escape from the matrix. Large particles embedded at longer time before they were broken down. The matrix area in contact with the abrasive suspension mixture surfaces was reduced by the effect of increasing $\mathrm{B}_{4} \mathrm{C}$ particle volume fraction. As the volume fraction and particle size of $\mathrm{B}_{4} \mathrm{C}$ particulates increase, the specific wear rate of the composites reduces.

As the volume fraction of $\mathrm{B}_{4} \mathrm{C}$ particles increased, the surface roughness parameter (Ra) decreased (Table 2 and 3 ). The wear resistance increased as a result of the bulk hardness increasing. This increasing in hardness was due to the increasing of the $\mathrm{B}_{4} \mathrm{C}$ volume fraction.

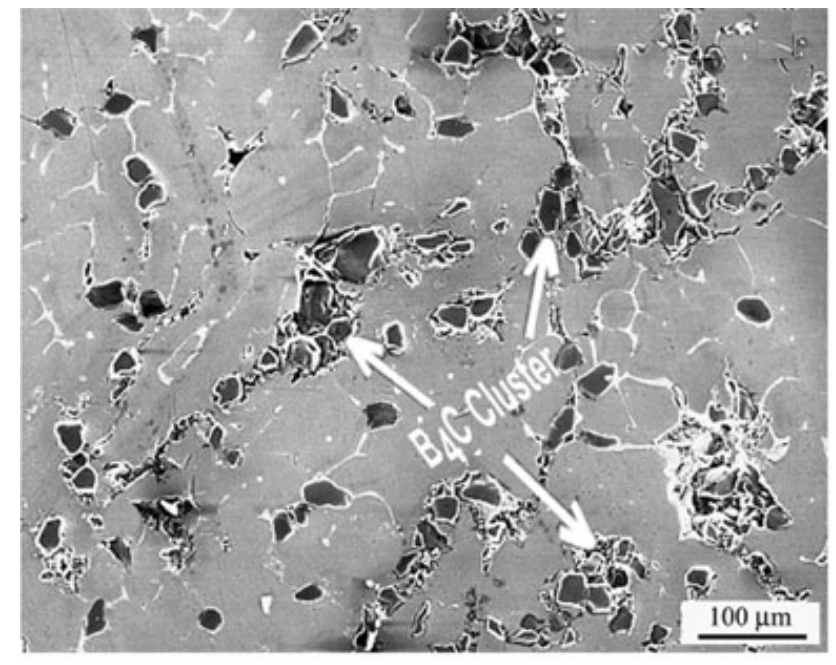

Figure 4. SEM image showing the distributions of $\mathrm{B}_{4} \mathrm{C}$ particles.. 
Table 3. Experiment data and predicted output from the ANN network for testing set

\begin{tabular}{|c|c|c|c|c|c|c|c|c|c|c|c|c|}
\hline \multirow{2}{*}{ Sample ID } & \multirow{2}{*}{$\begin{array}{c}\text { Particle } \\
\text { size }\end{array}$} & \multirow{2}{*}{$\begin{array}{c}\text { Sliding } \\
\text { time }\end{array}$} & \multirow{2}{*}{$\begin{array}{l}\text { Volume } \\
\text { fraction }\end{array}$} & \multicolumn{3}{|c|}{ Volume loss } & \multicolumn{3}{|c|}{ Specific wear rate } & \multicolumn{3}{|c|}{ Surface roughness } \\
\hline & & & & Measured & Predicted & $\%$ Error & Measured & Predicted & $\%$ Error & Measured & Predicted & $\%$ Error \\
\hline 3 & 71 & 200 & 5 & 1.083 & 1.015 & 6.32 & 0.187 & 0.173 & 7.54 & 4.248 & 4.460 & -4.99 \\
\hline 7 & 71 & 670 & 3 & 3.066 & 2.873 & 6.30 & 0.158 & 0.142 & 9.86 & 5.354 & 5.268 & 1.60 \\
\hline 10 & 71 & 670 & 10 & 1.267 & 1.134 & 10.48 & 0.065 & 0.069 & -6.71 & 3.878 & 4.214 & -8.66 \\
\hline 11 & 71 & 1140 & 0 & 5.036 & 5.249 & -4.24 & 0.153 & 0.164 & -7.06 & 6.193 & 6.294 & -1.62 \\
\hline 14 & 71 & 1140 & 7 & 3.345 & 3.575 & -6.88 & 0.102 & 0.102 & -0.03 & 4.226 & 3.743 & 11.43 \\
\hline 17 & 71 & 1610 & 3 & 6.223 & 5.879 & 5.53 & 0.134 & 0.131 & 2.21 & 5.478 & 5.359 & 2.18 \\
\hline 19 & 71 & 1610 & 7 & 4.430 & 4.580 & -3.39 & 0.095 & 0.100 & -5.58 & 3.719 & 4.068 & -9.37 \\
\hline 21 & 71 & 2080 & 0 & 8.004 & 8.085 & -1.01 & 0.133 & 0.140 & -5.25 & 6.699 & 6.586 & 1.68 \\
\hline 26 & 29 & 200 & 0 & 1.349 & 1.372 & -1.69 & 0.233 & 0.234 & -0.58 & 4.699 & 4.428 & 5.76 \\
\hline 30 & 29 & 200 & 10 & 0.634 & 0.649 & -2.38 & 0.110 & 0.128 & -15.92 & 4.277 & 4.168 & 2.54 \\
\hline 33 & 29 & 670 & 5 & 2.528 & 2.481 & 1.87 & 0.131 & 0.131 & -0.15 & 4.465 & 4.821 & -7.96 \\
\hline 37 & 29 & 1140 & 3 & 4.600 & 4.541 & 1.28 & 0.140 & 0.138 & 1.65 & 5.087 & 5.059 & 0.54 \\
\hline 40 & 29 & 1140 & 10 & 2.900 & 2.908 & -0.28 & 0.088 & 0.083 & 6.20 & 5.362 & 5.140 & 4.14 \\
\hline 43 & 29 & 1610 & 5 & 5.417 & 5.292 & 2.31 & 0.116 & 0.113 & 2.93 & 4.947 & 5.025 & -1.57 \\
\hline 47 & 29 & 2080 & 3 & 7.486 & 7.346 & 1.87 & 0.124 & 0.121 & 2.74 & 6.042 & 5.842 & 3.31 \\
\hline \multirow[t]{3}{*}{49} & 29 & 2080 & 7 & 6.148 & 6.177 & -0.48 & 0.102 & 0.101 & 0.54 & 5.419 & 5.372 & 0.87 \\
\hline & \multicolumn{3}{|c|}{ MAPE } & \multicolumn{3}{|c|}{3.519} & \multicolumn{3}{|c|}{4.685} & \multicolumn{3}{|c|}{4.264} \\
\hline & \multicolumn{3}{|c|}{ RMSE } & \multicolumn{3}{|c|}{0.148} & \multicolumn{3}{|c|}{0.008} & \multicolumn{3}{|c|}{0.233} \\
\hline
\end{tabular}

\subsection{Prediction Capacity of the ANN}

The predicted values, deviation and \% error for the volume loss, specific wear rate and surface roughness are provided in Tables 2 and 3. The ANN was tested for accuracy using the test values (Table 3) selected from the experimental results that were not used during the learning processes

In most cases, the neural network prediction is very close to the actual value. However, several values are not as close as others, which is due to the errors caused by the material, the measurements and process parameters. However, these errors could be neglected given that the learning level of the artificial neural network is $95 \%$. This study revealed that the predictions made using the ANN produced more accurate results.

The mean absolute percentage error (MAPE) was used to evaluate the performance of the proposed ANN as a prediction technique. The mean absolute percentage errors (MAPE) were $3.519 \%$ for the volume loss, $4.685 \%$ for specific wear rate and $4.264 \%$ for surface roughness. With respect to the results obtained from the plots of the ANN prediction, the highest MAPE value of $4.685 \%$ demonstrates that the network effectively generates sensitive results.

A comparison of the measured and predicted (ANN) volume loss, specific wear rate and surface roughness, at the testing stage is provided in Fig. 5.

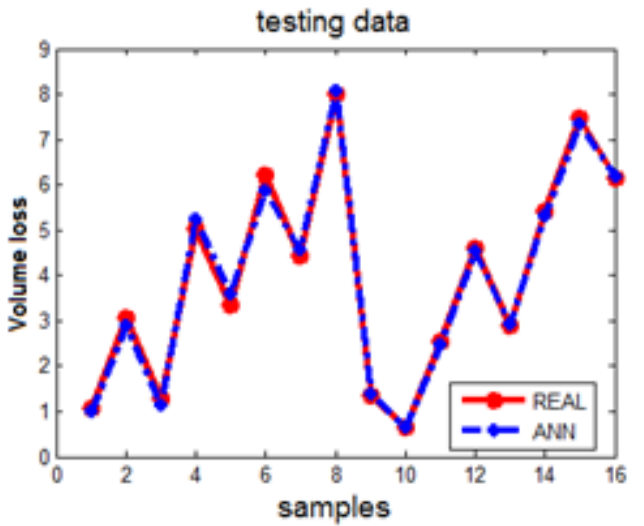

(a)

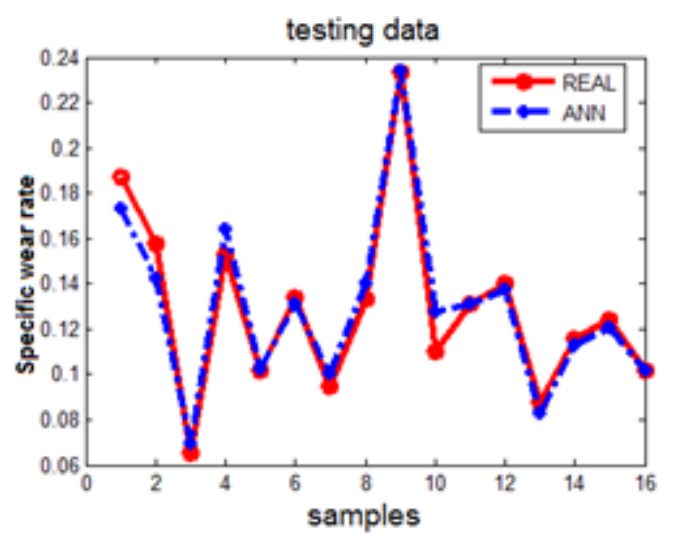

(b) 


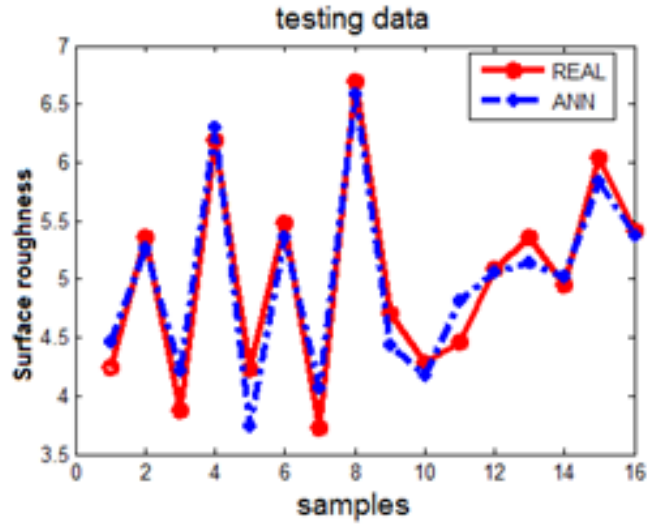

(c)

Figure 5. The comparison of measured values and ANN values for (a) volume loss; (b) specific wear rate; (c) surface roughness.

From these comparison charts, it can be clearly observed that the ANN is properly trained and shows consistency in predicting the properties of the powder. A comparison between the measured and predicted composite powder properties at the testing stage indicates a high correlation. In other words, the results of the comparison plots indicate the similarities between the experimental study and the ANN model, and support the reliability of the model. The comparison diagrams reveal that the slope and intercept of the regression equations for the outputs are very close to 1 and 0 , respectively. The correlation coefficient was obtained to be 0.99 , indicating good agreement between the experimental results and the model prediction (For testing data set: $R_{\text {volume loss }}=0.99788, R_{\text {specific wear rate }}=0.97904$, $\left.\mathrm{R}_{\text {surface roughness }}=0.9604\right)$. The statistical results, namely the root-mean squared error (RMSE) and the mean absolute percentage error (MAPE), are within an acceptable range and meet the integrity of the ANN learning and testing stages. Thus, reasonable agreement between the predicted and experimental data supports the accuracy of the model.

\section{Conclusions}

The use of ANN to study the effect of the sliding time, volume fraction and ceramic particle size on the volume loss, specific wear rate and surface roughness of $\mathrm{Al} 2024 / \mathrm{B}_{4} \mathrm{C}$ composites was explored in this study. The ANN model generates satisfactory results when compared to the experimental measurements. The mean absolute percentage error (MAPE) for predicted values does not exceed $4.685 \%$. Therefore, with the use of ANN values, satisfactory results can be estimated rather than measured, which thereby reduces the testing time and cost. Moreover, the abrasive wear properties of the $2024 \mathrm{Al}$ alloy were considerably improved by the addition of $\mathrm{B}_{4} \mathrm{C}$ particles, and the abrasive wear resistance of the composites was found to be much higher than that of the unreinforced $2024 \mathrm{Al}$ alloy. The harder $\mathrm{B}_{4} \mathrm{C}$ particles provide the major contribution for the abrasive wear resistance. The abrasive wear resistance of the composites is increased with increasing $\mathrm{B}_{4} \mathrm{C}$ particle content and size.

\section{Acknowledgements}

This study was mainly supported by the Scientific Research Projects of Karadeniz Technical University (no. 21.112.003.7). The authors would like to thank Wacker Ceramics for their support in kindly supplying the $\mathrm{B}_{4} \mathrm{C}$ particles.

\section{REFERENCES}

[1] Canakci A, Varol T \& Ertok S, Sci Eng Compos Mater, Vol.19,227-235, 2012.

[2] Guo J, Gougeon P \& Chen X G, Composites: Part B, Vol.43, 2400-2408, 2012.

[3] Varol T, Canakci A \& Ozsahin S, Composites: Part B, Vol.54, 224-233, 2013.

[4] Mazahery A \& Shabani M O, Journal of Materials Science, Vol. 46, 6700-6708, 2011.

[5] Kaczmar J W, Pietrzak K \& Wlosinski W, Journal of Materials Process Technology, Vol. 106, 58-67, 2010.

[6] Canakci A, Varol T \& Ozsahin S, Metallurgy and Materials International, Vol 19 ,519-526, 2013.

[7] Mohanty R M, Balasubramanian K \& Seshadri S K, Materials Science Engineering A, Vol. 498, 42-52, 2008.

[8] Saravanan R A \& Surappa M K, Materials Science and Engineering A, Vol. 276, 108-116, 2000.

[9] Ferkel H \& Mordike B L, Materials Science and Engineering A, Vol. 298, 193-199, 2001.

[10] Poddar P, Srivastava V C, De P K \& Sahoo K L, Materials Science and Engineering A, 460-461, 357-364, 2007.

[11] Ozyurek D, Kalyon A, Yıldırım M, Tuncay T, Ciftci I, Materials Design, Vol. 63, 270-277, 2014.

[12] Rashed FS, Mahmoud TS, Tribology International Vol. 42, 642-648, 2009.

[13] Mohsen Ostad Shabani, Ali Mazahery, Synthetic Metals Vol. 161, 1226-1231, 2011.

[14] Malinov S \& Sha W, Comput Mater Sci, Vol. 28, 179-198, 2003.

[15] Canakci A, J Mater Sci Vol. 46, 2805-2813, 2011.

[16] Lee J A, Almond D P \& Harris B, Composites: Part A, Vol. $30,1159-1169,1999$.

[17] Senatore A, Agostino V D, Giuda R D \& Petrone V, Tribology International,Vol. 44, 1199-1207, 2011.

[18] Ma J, Zhu S G, Wu C X \& Zhang M L, Materials Design, Vol. 30, 2867-2874, 2009.

[19] Sagiroglu S, Besdok E \& Erler M, Artificial intelligence 
applications in engineering-1: Artificial neural networks, Kayseri, 2003.

[20] Kök M, Composite Part A, 37, 457-464, 2006.

[21] Ma Z Y, Liang Y N, Zhang Y Z, Lu Y X \& Bi, Journal of Materials Science and Technology, 12, 751-756, 1996.

[22] Tjong S C \& Lau K C, Materials Science and Engineering A,
$282,183-186,2000$

[23] Canakci A, Manufacturing of AA2024 matrix-B4C particle reinforced composites by vortexmethod and investigation of their properties, Ph.D. thesis, Karadeniz Technical University, Trabzon, 2006

[24] Kumar S \& Balasubramanian V, Tribology International, 43, 414-422, 2010. 